\title{
Deformation behavior of $\gamma$-TiAl composites in the solid and mushy states
}

\author{
K. Makhlouf and A. K. Ghosh \\ The University of Michigan, Materials Science and Engineering Department, Ann Arbor, MI 48109 (USA) \\ R. Ray \\ Marko Materials, 19-1 Sterling Road, N. Billerica, MA 0182 (USA)
}

(Received May 27, 1993; in revised form July 26, 1993)

\begin{abstract}
The deformation behavior of a two phase $\left(\gamma+\alpha_{2}\right)$ lamellar TiAl alloy reinforced with various amounts of $\mathrm{AlTi} \mathrm{i}_{2} \mathrm{C}$ carbide platelets has been examined by determining Vickers hardness at room temperature and in the temperature range $900-1300^{\circ} \mathrm{C}$. The compression flow behavior of these materials has also been examined in the semi-solid state. The hardness values for all materials dropped from about $4 \mathrm{GPa}$ at room temperature to $120 \mathrm{MPa}$ at $1300^{\circ} \mathrm{C}$. The composites exhibited limited increase in hardness with respect to the base material over most of the temperature range investigated. At $900{ }^{\circ} \mathrm{C}$, however, the $13 \% \mathrm{AlTi}_{2} \mathrm{C}$ reinforced composite showed an increase in hardness of about 1.2 $\mathrm{GPa}$ over that of the base material. The composites exhibited interfacial as well as transgranular cracks induced by indentations, while the matrix material did not exhibit cracking during the hardness tests. Forgeability of semi-solid $\mathrm{Ti}-48 \mathrm{Al}$ reinforced with $13 \% \mathrm{AlTi}_{2} \mathrm{C}$ composite was studied by performing compression tests at $1470{ }^{\circ} \mathrm{C}$ and strain rates ranging from 0.33 to $2.00 \mathrm{~s}^{-1}$. Stress-strain curves exhibited a peak stress which is associated with breakdown of the carbide platelets. The size of the carbide platelets decreased and their reorientation took place with increasing strain. At strains higher than 0.9 , reagglomeration of the carbide platelets was observed.
\end{abstract}

\section{Introduction}

Titanium aluminides are attractive materials for high temperature structural applications, because of their high melting temperature, good elevated temperature strength, and high resistance to oxidation. In addition, these materials possess low density and high modulus. On the other hand, the poor ductility of these materials at low and intermediate temperatures resulting in low fracture toughness and low fatigue crack growth resistance, has limited their use [1-3]. However, over the past few years, a remarkable improvement in the properties (such as ductility, toughness and creep resistance) has been achieved through alloying and controlling the microstructure during processing [4-11]. These improvements have made these materials potentially viable engineering alloys for aerospace and automotive applications especially because of their light weight $[12,13]$.

The deformation behavior of $\gamma-\mathrm{TiAl}$ has been studied extensively and is related to the ordered facecentered tetragonal structure in which $\mathrm{Ti}$ and $\mathrm{Al}$ atoms occupy alternating (002) planes. Deformation generally involves ordinary dislocations of type $1 / 2[110]$ and superdislocations of type [101] and $1 / 2[112]$. How- ever, the deformation mechanisms for single and duplex microstructures are different $[14,15]$. Room temperature tensile strains greater than $2.5 \%$ were measured on duplex microstructures compared with only $0.5 \%-1 \%$ measured on single phase $\gamma-\mathrm{TiAl}$ microstructures $[16,17]$. At elevated temperature, it was reported that the yield strength in $\mathrm{TiAl}$ reaches a maximum at a temperature of $600^{\circ} \mathrm{C}$ for single crystals and $800{ }^{\circ} \mathrm{C}$ for polycrystalline materials. This increase of yield strength with temperature is associated with a hardening mechanism involving cross-slip and pinning of partial dislocations [14] or by entanglement of $1 / 2\langle 110\rangle$ dislocations by dislocation loops and spiral segments $[18,19]$.

Recently, there has been further interest in enhancing the mechanical and physical properties of these intermetallics through the addition of a reinforcement phase. Christodoulou et al. reported that the addition of $\mathrm{TiB}_{2}$ to $\mathrm{TiAl}$ substantially increases the fracture toughness and creep strength of the alloy without compromising the other desirable properties [20]. Toughening mechanisms such as crack tip blunting generally by ductile phase, crack deflection, crack bridging and microcrack formation in the wake of a propagating crack, were responsible for the increase in 
toughness $[4,21]$. However, characterization of the deformation behavior of these intermetallic composites have not been investigated in detail.

Various testing techniques have been used to evaluate the mechanical properties of intermetallic matrix composites. In addition to standard tensile and compression testing, microhardness indentation offers another technique which is often used to obtain a rapid evaluation of the deformation behavior of materials. It also provides a method for estimation of fracture toughness. Indentation hardness is defined as the resistance to indentation or penetration, and is generally performed by pressing a hard indentor of specific geometry into the surface of the sample. Conducting hardness tests as a function of temperature can allow an assessment of deformation processes and mechanisms. This test requires special indentors which do not deform at high temperature.

Intermetallic matrix composite parts can be produced by conventional casting followed by appropriate thermomechanical processing and machining. However, these approaches are technologically challenging and very expensive. Therefore, strong interest exists in net shape processing of these materials in the semisolid state to produce components of complex configuration and reduce machining requirements.

Processing methodology in the semi-solid state was introduced in the late $1970 \mathrm{~s}$ by Flemings and coworkers at MIT [22-25]. This technique has been used lately to produce net or near net shape components. Processing of materials in the semi-solid state has numerous advantages over the conventional processing techniques. The most prominent advantage is the increase in the die life by either reducing the operation temperature used in die casting where the material is fully liquid, or reducing the applied force used in the forging operation where the material is fully solid. Laxmanan and Flemings [24] reported forging pressures for semi-solid alloys that are about three orders of magnitude lower than the forging pressures used in forging fully solid alloys.

Processing of materials in the semi-solid state is based on the creation of a special non-dendritic microstructure such that the solid fraction of the semi-solid slurry appears as spheroids or nodules. This has significant advantages over the dendritic counterpart. Laxmanan and Flemings [24] reported that the forging pressures of non-dendritic alloy is about two orders of magnitude lower than the forging pressures of semisolid dendritic alloy. The formation of a non-dendritic alloy structure is generally achieved by vigorously agitating the liquid during solidification. For a nondendritic material, the deformation behavior in a semisolid material follows the non-Newtonian power law behavior described by: $\mu=m \gamma^{n-1}$, where $\mu$ is the viscosity, $\gamma$ the shear rate, $m$ is called the consistency and $n$ the power law index. Both $m$ and $n$ are constants. However, for a dendritic microstructure, it was reported that at all strain rates, there is a critical strain at which the strength reaches a maximum and then starts to decrease [26]. The decrease in strength is attributed to the breakdown of the dendrites. In addition, the maximum stress associated with dendrites breakdown was found to increase and shift to higher strains with increasing strain rate.

The objective of the work described here is to examine the deformation behavior of $\gamma+\alpha_{2}$-TiAl composites containing carbide platelets over a wide temperature range and examine the damage to the platelets. The work is divided into two parts. The first part will involve the determination of the hardness behavior of the base material Ti-48 Al and Ti-48 Al reinforced with $6 \%, 10 \%$ and $13 \%$ carbide phase at room temperature and in the temperature range $900-1300^{\circ} \mathrm{C}$. The second part will deal essentially with the compression behavior of a partially remelted $\mathrm{Ti}-48 \mathrm{Al}$ composite containing $13 \%$ carbide phase over a range of strain rates. The practical side of the work is to determine the optimum combination of the experimental variables $(\dot{\varepsilon}, T)$ at which the material can be homogeneously deformed in the forging operation with the least cavity formation.

\section{Materials}

Fabrication of titanium aluminide composites was performed in the following manner: titanium sponge of purity greater than $99.9 \%, 99.99 \%$ high purity aluminum shots and $\mathrm{TiC}$ powder were used as starting materials. The materials were produced as ingots (10 $\mathrm{cm}$ diameter and $4 \mathrm{~cm}$ thickness) by non-consumable arc melting in a water-cooled copper heater followed by casting the melt in a water-cooled copper mold. The cast ingots were hot pressed for $4 \mathrm{~h}$ at $1300{ }^{\circ} \mathrm{C}$ under a pressure of $103 \mathrm{MPa}$. The material obtained consists of a lamellar $\left(\gamma-\mathrm{TiAl}\right.$ and $\left.\alpha_{2}-\mathrm{Ti}_{3} \mathrm{Al}\right)$ microstructure reinforced with a platelet-shaped carbide phase which was identified by Ayer et al. [27] to be the $\mathrm{AlTi}_{2} \mathrm{C}$ phase. Three composites of $6 \%, 10 \%$ and $13 \%$ by volume of $\mathrm{AlTi}_{2} \mathrm{C}$ were produced using this method. The microstructures of these composites are shown in Fig. 1. The matrix which is based on $\mathrm{Ti}-48$ at.\% $\mathrm{Al}$ consists of lamellar grains of a few dozen microns in diameter within which the platelets are randomly distributed. It is reported that the $\gamma$-phase was internally twinned on the $\{111\}$. Twins of type [112], [121] and [211] were identified by transmission electron microscopy (TEM) studies [27]. However, $\alpha_{2}$ did not show any twinning. The carbide platelets are presumed to 

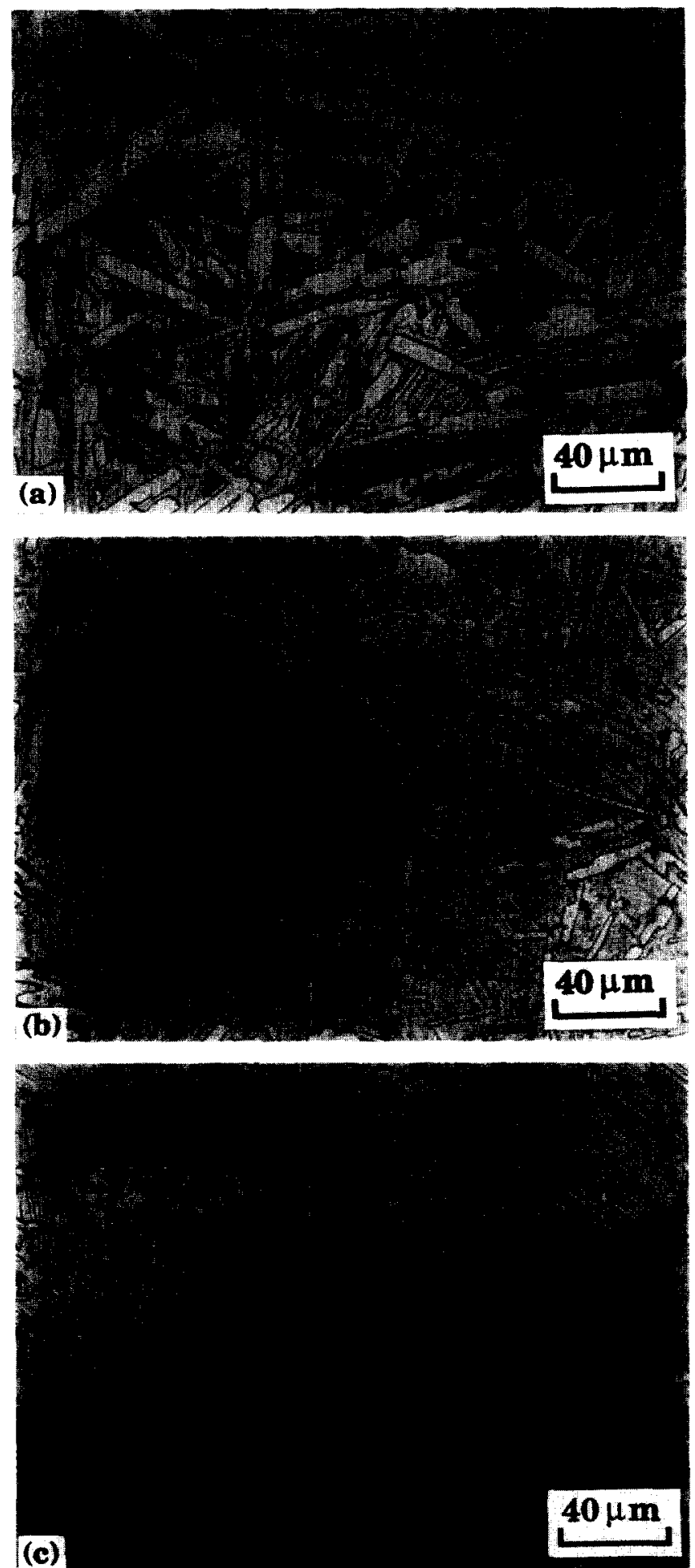

Fig. 1. Optical micrographs showing the as-received microstructures of $\mathrm{Ti}-48 \mathrm{Al}$ reinforced with (a) $13 \% \mathrm{AlTi}_{2} \mathrm{C}$, (b) $10 \%$ $\mathrm{AlTi}_{2} \mathrm{C}$, (c) $6 \% \mathrm{AlTi}_{2} \mathrm{C}$.

have hexagonal crystal structure and might be produced by preferential growth of the carbide perpendicular to the $c$-direction during solidification $[27,28]$. The aspect ratio of these platelets ranging from 1 to 28 had a mean value of 8 .

\section{Experimental procedures}

Three composite materials with $6 \%, 10 \%$ and $13 \%$ $\mathrm{AlTi}_{2} \mathrm{C}$, as well as the base $\mathrm{Ti}-48 \mathrm{Al}$ material were produced and their mechanical behavior investigated using either hardness testing or compression testing in the semi-solid state.

\subsection{Hardness measurements}

The Vickers hardness $(\mathrm{VH})$ has been determined on $5 \times 5 \times 10 \mathrm{~mm}^{3}$ samples of $\mathrm{Ti}-48 \mathrm{Al}$ reinforced with $0 \%, 6 \%, 10 \%$ and $13 \%$ by volume of $\mathrm{AlTi}_{2} \mathrm{C}$ phase at room temperature and in the temperature range $900-1300^{\circ} \mathrm{C}$. The room temperature $\mathrm{VH}$ has been determined using a Tukon tester. The hardness was measured at four different loads of $1,10,20$ and $30 \mathrm{~kg}$. At each load, an average of eight indentations were produced. The elevated temperature hardness tests were performed on a Nikon hot hardness test apparatus using a sapphire indentor in a vacuum environment. The applied load was set at $1 \mathrm{~kg}$ during testing. Optical micrographs of the indentations were taken and their diagonal sizes were measured and averaged to determine VH. The Vickers hardness at each load and temperature was determined using the following equation:

\section{$V H=1.854 P / d^{2}$}

In this equation, $P$ is the applied load in kilograms and $d$ is the average length of the diagonals of the indentation expressed in millimeters. The hardness was calculated at each load and each temperature and later was expressed in giga pascals as a measure of resistance to deformation. The samples were sectioned along the diagonals of the indentations for metallographic examination which was performed on a Nikon optical microscope.

\subsection{Compression testing}

Two sizes of cylindrical sample $(9.53 \mathrm{~mm}$ diameter and $12.7 \mathrm{~mm}$ height, $6.4 \mathrm{~mm}$ diameter and $4.6 \mathrm{~mm}$ height) of $\mathrm{Ti}-48 \mathrm{Al}$ reinforced with $13 \%$ platelets by volume of $\mathrm{AlTi}_{2} \mathrm{C}$ were squeezed between the two parallel graphite platens located in the center of a cubic stainless steel furnace made by Centorr Associates. Heating of the samples was achieved by tungsten wire mesh elements. The temperature was controlled using two thermocouples placed very close to the sample but touching the upper graphite platen which is fixed. The upper graphite platen was attached to the upper grip in order to prevent any squeezing of the samples during heating or when the temperature is stabilizing after it reaches the setup temperature. The tests were conducted at $1470 \pm 10^{\circ} \mathrm{C}$ in an argon environment. This temperature lies between $T 1$ and $T 2$ which represent 
the temperature range at which both solid and liquid exist. This is depicted in the phase diagram [29,30] shown in Fig. 2. All compression tests were performed on an Instron testing machine of $100 \mathrm{KN}$ load capacity equipped with a computerized data acquisition system. The initial strain rate during these tests was ranging from 0.33 to $2.00 \mathrm{~s}^{-1}$ depending on the specimen size and the cross-head speeds which were selected to be 254 or $508 \mathrm{~mm} \mathrm{~min}^{-1}$. The computer acquires load-displacement curves which were then converted into true stress-true strain curves assuming constant volume. After the compression experiments, the samples were sectioned along the vertical axis for metallographic examination which was performed on a Nikon optical microscope.

\section{Results and discussion}

\subsection{Hardness testing}

Figure 3 shows hardness values generated at room temperature for all four materials expressed as a function of applied load. As expected, the hardness of each material at each load is relatively the same for all loads, except that at $1 \mathrm{~kg}$ the values are slightly higher than at the other loads. At loads higher than $1 \mathrm{~kg}$, the hardness values ranged from $3.5 \mathrm{GPa}$ in the base

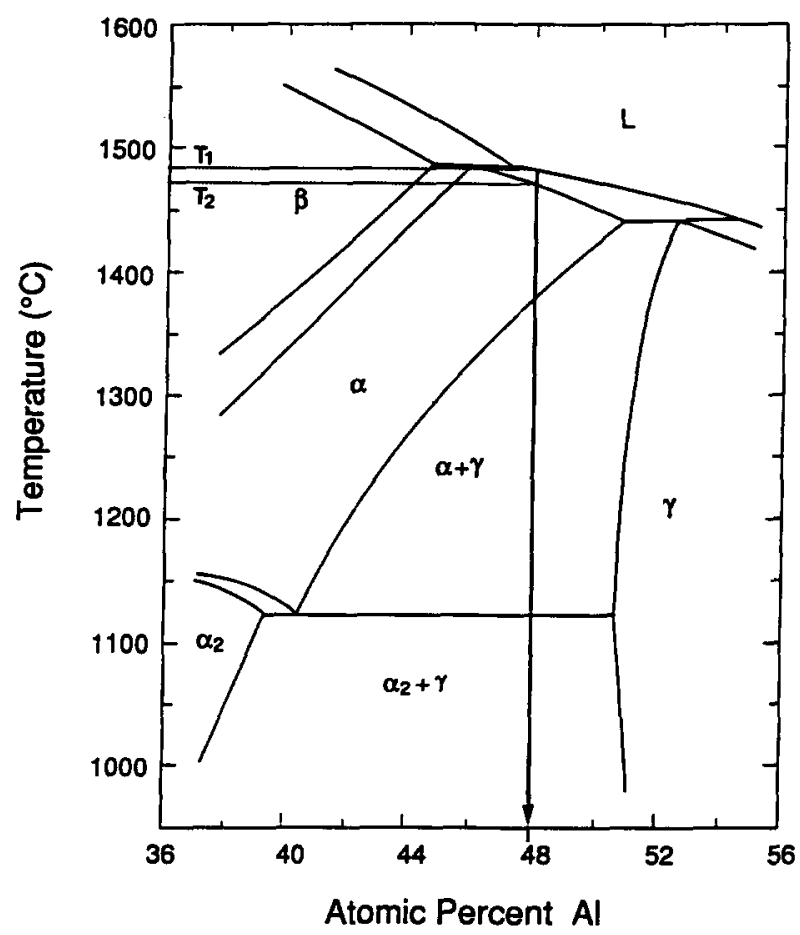

Fig. 2. A partial $\mathrm{Ti}-\mathrm{Al}$ phase diagram showing the composition ( $\mathrm{Ti}-48 \mathrm{Al}$ ) of the base material used in this study and the temperature range $(T 1-T 2)$ within which both liquid and solid are present $[19,31]$.

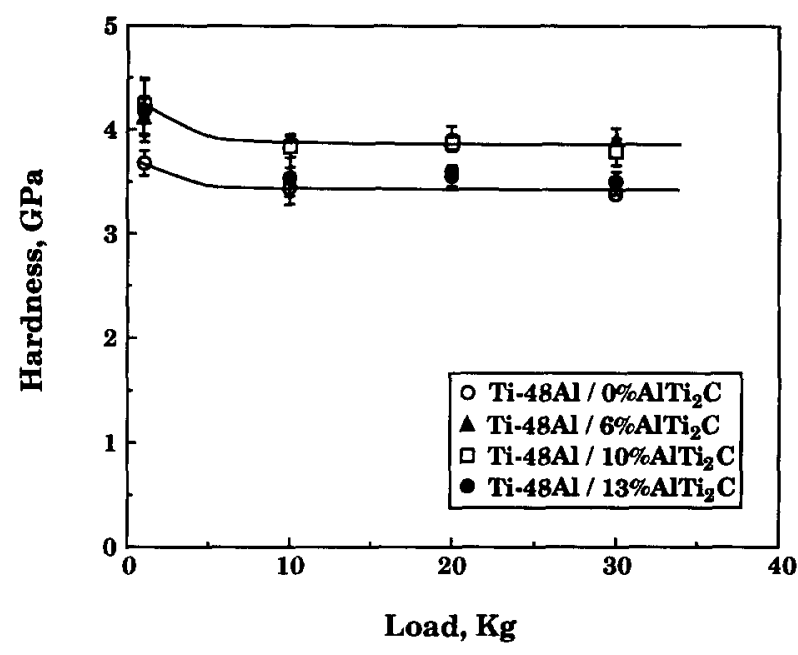

Fig. 3. Room temperature hardness as a function of applied load for all test materials studied.
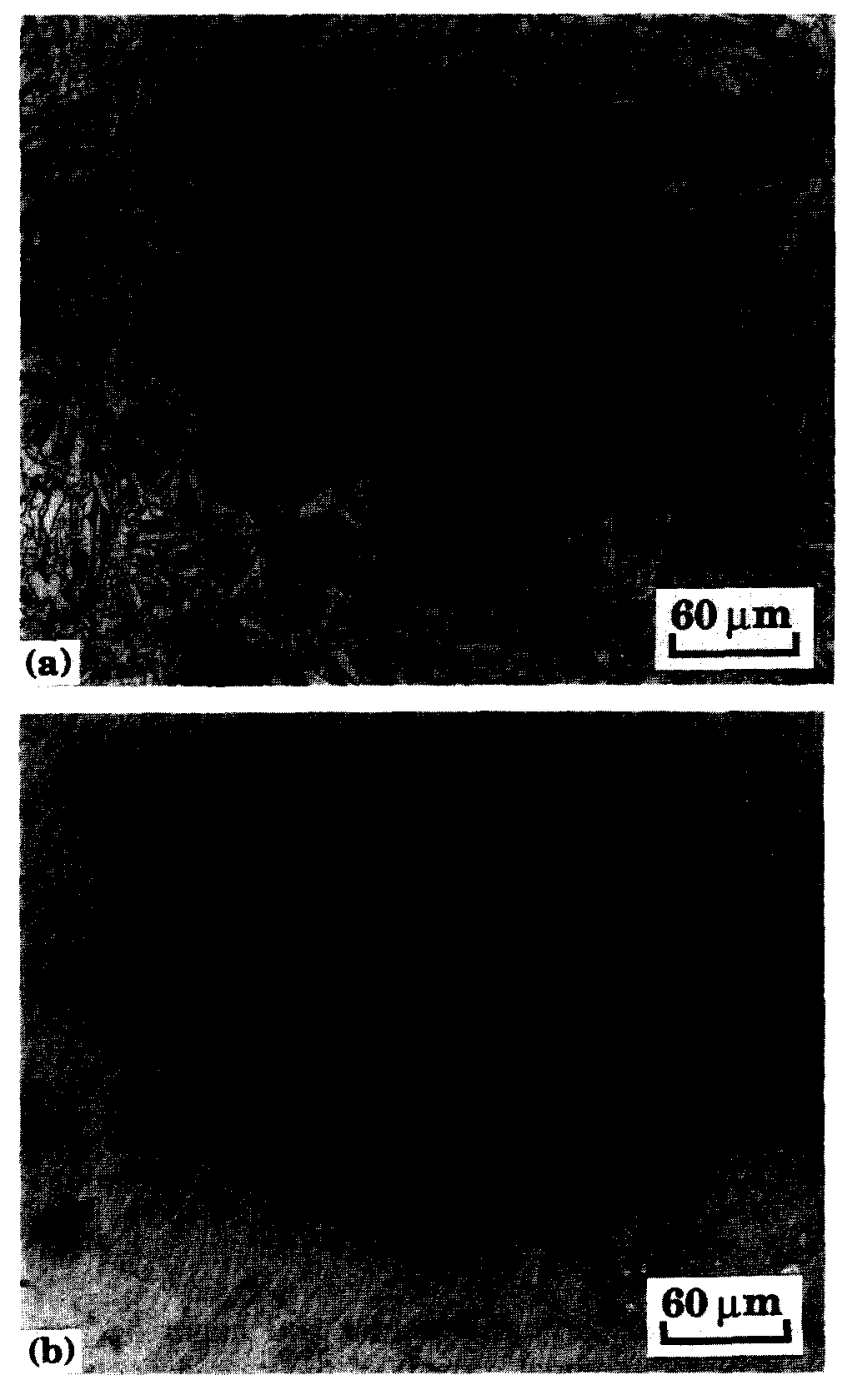

Fig. 4. Optical micrographs showing indentations of room temperature hardness tests performed on (a) $\mathrm{Ti}-48 \mathrm{Al} / 13 \%$ $\mathrm{AlTi}_{2} \mathrm{C}$ composite, (b) $\mathrm{Ti}-48 \mathrm{Al}$ base material. Applied load $=10 \mathrm{~kg}$. 

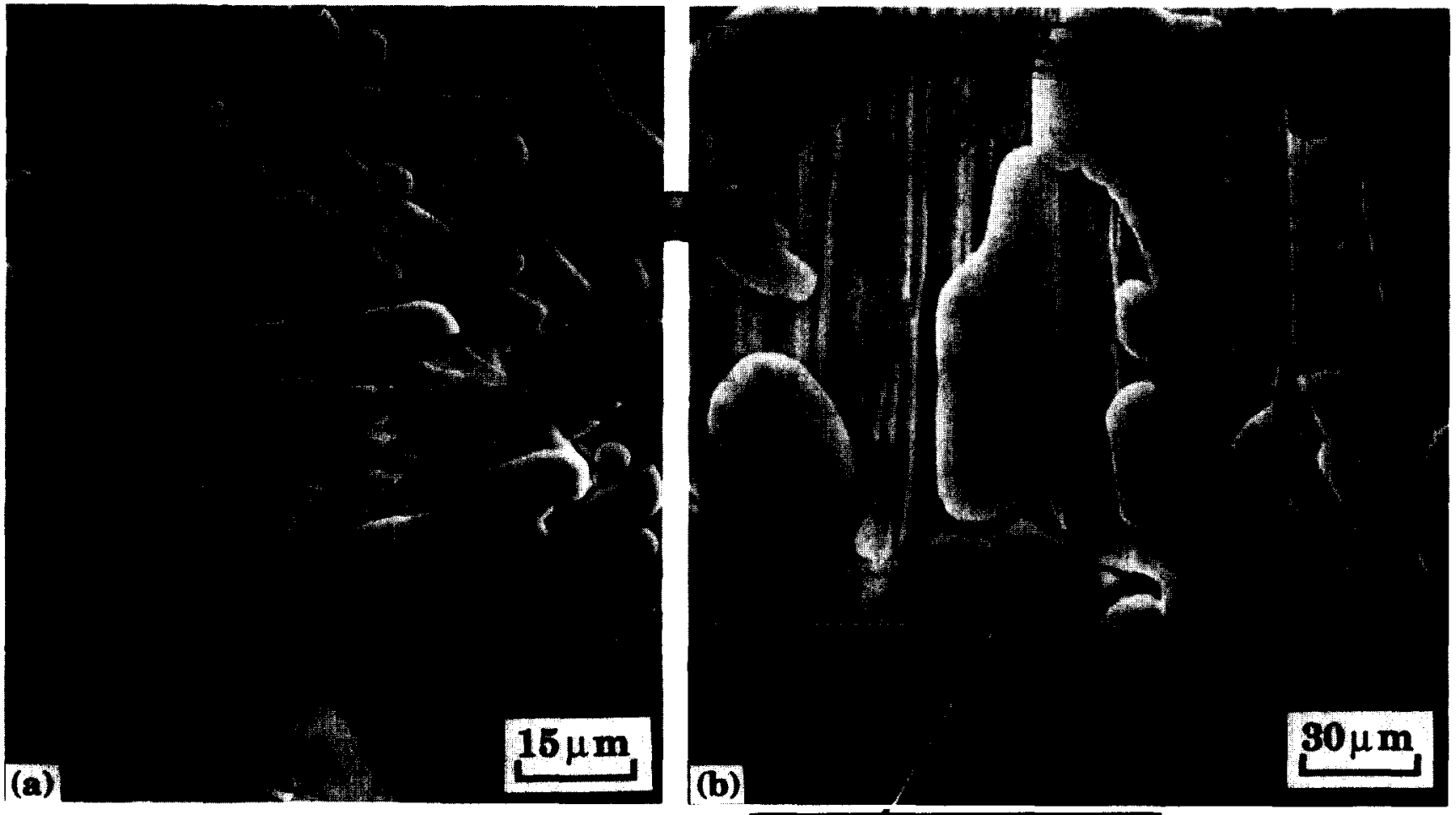

Edge of Indentation

Fig. 5. SEM images showing features of an indentation performed on the $\mathrm{Ti}-48 \mathrm{Al} / 13 \% \mathrm{AlTi}{ }_{2} \mathrm{C}$ composite at room temperature (a) at the corner of indentation, (b) on the edge of indentation. Applied load $=30 \mathrm{~kg}$.

material to $3.9 \mathrm{GPa}$ for the $6 \% \mathrm{AlTi}_{2} \mathrm{C}$ reinforced material. The $10 \%$ and $13 \% \quad \mathrm{AlTi}_{2} \mathrm{C}$ reinforced materials exhibited hardness values of 3.57 and 3.85 GPa, respectively. The slightly higher hardness values measured at $1 \mathrm{~kg}$ could be associated with the elastic recovery of indentation during unloading. It is believed that at small loads, the elastic recovery of the indentation diagonals is more pronounced than at higher loads leading to an apparent increase in hardness values at low loads [29].

Figures $4(a)$ and $4(b)$ show optical micrographs of two indentations performed at room temperature on the $\mathrm{Ti}-48 \mathrm{Al} / 13 \% \mathrm{AlTi}_{2} \mathrm{C}$ composite and on the base material $\mathrm{Ti}-48 \mathrm{Al}$, respectively. These micrographs were for indentations performed at $10 \mathrm{~kg}$. It is possible to see from these micrographs that fine scale damage is visible around the edges of indentation for the composite material but not for the base material. The edges of indentation are also curved inward for the composite indicative of its higher elastic springback in comparison to the matrix alloy. Greater details of microcracks in the composite are shown in Fig. 5. Microcracks are formed at the corners as well as on the edges of the indentations performed on the composite. These microcracks are seen to propagate into the matrix material, along the interface as well as in the
$\mathrm{AlTi}_{2} \mathrm{C}$ platelets. It appears that the platelets mostly fracture along their longitudinal direction indicating a weak crystallographic plane (cleavage) in that direction. However, in the unreinforced material, no microcracks are observed. Slip lines are produced around the indentations as seen in Fig. 5(b). It could be suggested that during indentation, dislocation plasticity is the principal deformation mechanism in the matrix material.

Figure 6 shows Vickers hardness expressed as a function of temperature for the base material and for the $\mathrm{Ti}-48 \mathrm{Al}$ reinforced with $6 \%, 10 \%$ and $13 \%$ $\mathrm{AlTi}_{2} \mathrm{C}$ composites. As expected, the hardness for all materials decreased significantly with increasing the temperature from 900 to $1300{ }^{\circ} \mathrm{C}$. However, at $900{ }^{\circ} \mathrm{C}$, the $\mathrm{Ti}-48 \mathrm{Al} / 13 \% \mathrm{AlTi}_{2} \mathrm{C}$ showed greater resistance to deformation than the other materials, this improvement in resistance to deformation decreased with decreasing $\mathrm{AlTi}_{2} \mathrm{C}$ content. Moreover, at temperatures higher than $900{ }^{\circ} \mathrm{C}$, the difference in hardness was less pronounced and decreased with increasing temperature.

To examine the indentation-induced damage further, cross-sectional views through the indentations were examined as shown in Fig. 7. Figures $7(\mathbf{a})$ and $7(\mathbf{b})$ show cross-sectional views of indentations performed 
on the $13 \% \mathrm{AlTi}_{2} \mathrm{C}$ composite and on the base material at room temperature at a load of $30 \mathrm{~kg}$, whereas Fig. 7(c) shows a cross-sectional area of an indentation performed on the $13 \% \mathrm{AlTi}_{2} \mathrm{C}$ composite at $1300^{\circ} \mathrm{C}$ at a load of $1 \mathrm{~kg}$. Extremely minor microcracking is observed in the composite after room temperature indentation. The reason why these microcracks are much smaller than those in Figs. 4 and 5 is due possibly to the presence of a hydrostatic compressive state of stress underneath the indentor. The unreinforced matrix shows a smooth indentation surface which is free from microcracks. The elevated temperature indentation (Fig. 7(c)) shows, however, some evidence of microcracking and surface roughening possibly due to initial sticking between the indentor and the test material at $1300{ }^{\circ} \mathrm{C}$, followed by separation from each other when the indentor was retracted. This observation indicates that these materials possess a greater degree of toughness at room temperature as well as at $1300{ }^{\circ} \mathrm{C}$ when compared with $\mathrm{MoSi}_{2}$ or ceramic materials [30].

\subsection{Compression testing}

In order to investigate the forgeability of this $\mathrm{Ti}-48$ Al reinforced with $13 \% \mathrm{AlTi}_{2} \mathrm{C}$ composite, compression tests were performed at high strain rates using a high speed Instron machine. Figure 8 shows true stress vs. true strain data generated at $1470{ }^{\circ} \mathrm{C}$ at strain rates of $0.33,0.67$ and $2.03 \mathrm{~s}^{-1}$ respectively. It is clear that strain rate had a significant effect on ther behavior of this material but the initial loads were not very consistent. The initial part of the curve generated at $0.33 \mathrm{~s}^{-1}$ contains some degree of scatter. This behavior might be attributed to variation in the temperature since a slight change in the temperature, especially close to the
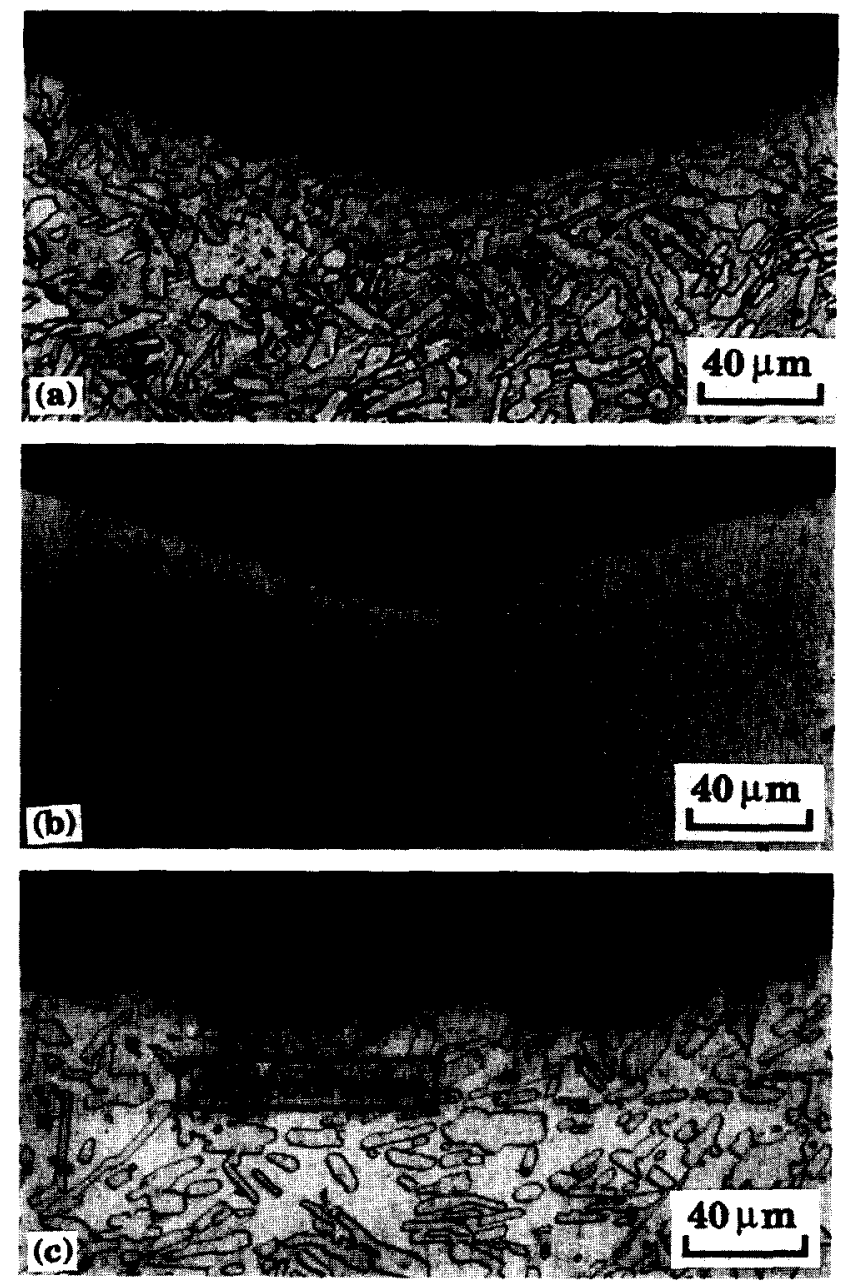

Fig. 7. Optical micrographs showing cross-sectional views of indentations made on (a) $\mathrm{Ti}-48 \mathrm{Al} / 13 \% \mathrm{AlTi}_{2} \mathrm{C}$ at room temperature, (b) $\mathrm{Ti}-48 \mathrm{Al}$ at room temperature and (c) $\mathrm{Ti}-48 \mathrm{Al} /$ $13 \% \mathrm{AlTi}_{2} \mathrm{C}$ at $1300{ }^{\circ} \mathrm{C}$. Applied load $=1 \mathrm{~kg}$.

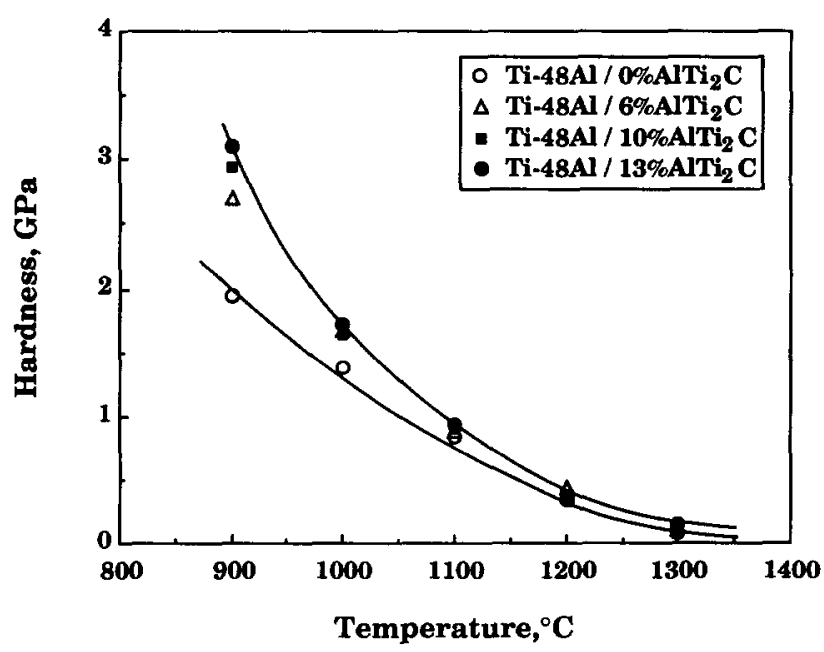

Fig. 6. Vickers hardness data of all test materials studied as a function of temperature (from Nikon hot hardness tester).

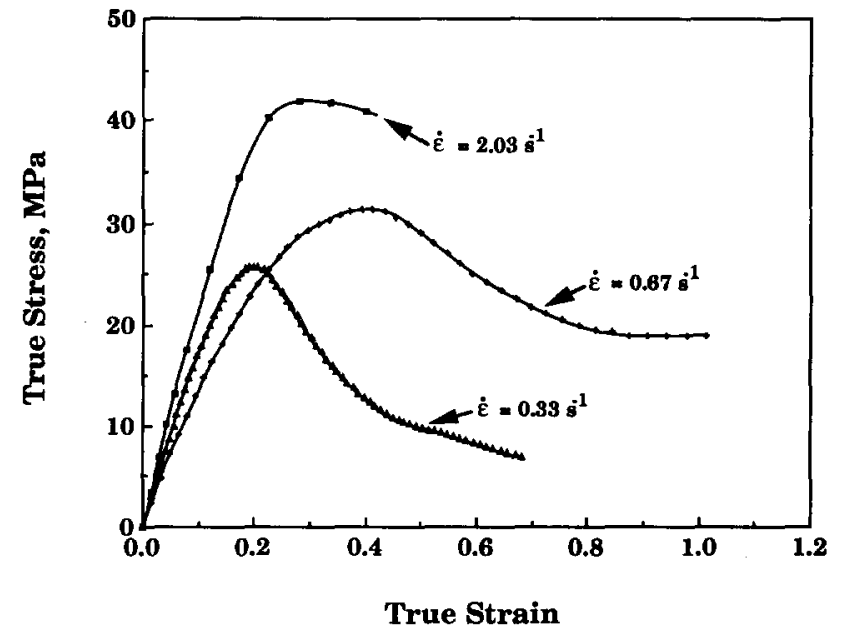

Fig. 8. True stress $v s$. true strain data for $\mathrm{Ti}-48 \mathrm{Al} / 13 \% \mathrm{AlTi}_{2} \mathrm{C}$ deformed at different strains rates at $1470{ }^{\circ} \mathrm{C}$ (in the semi-solid range). 
melting temperature, would significantly affect the behavior of the material. However, each curve exhibited a maximum stress before softening of the material is observed. This maximum stress increased with increasing strain rate for all tests. Also, the peak strain at which this maximum stress is observed is also seen to increase from 0.2 to 0.41 with increasing strain rate from 0.33 to $0.67 \mathrm{~s}^{-1}$. The test performed at $2.03 \mathrm{~s}^{-1}$, however, exhibited maximum stress at a strain of 0.3 which is lower than the 0.41 for test generated at $0.67 \mathrm{~s}^{-1}$. This effect may be related to internal fracture within the composite at high strain rates. The decrease in strength after it reaches maximum stress has also been observed in the semi-solid dendritic materials by other investigators and was attributed to the breakdown of the dendrites [23, 24]. In this material, a similar analogy could be made in which the reinforcement $\mathrm{AlTi}_{2} \mathrm{C}$ platelets were found to break and decrease in size with increasing strain.

Figure 9 shows optical micrographs of samples deformed to strain levels of 0.34 and 0.92 and 1.63 respectively, compared with that of an undeformed
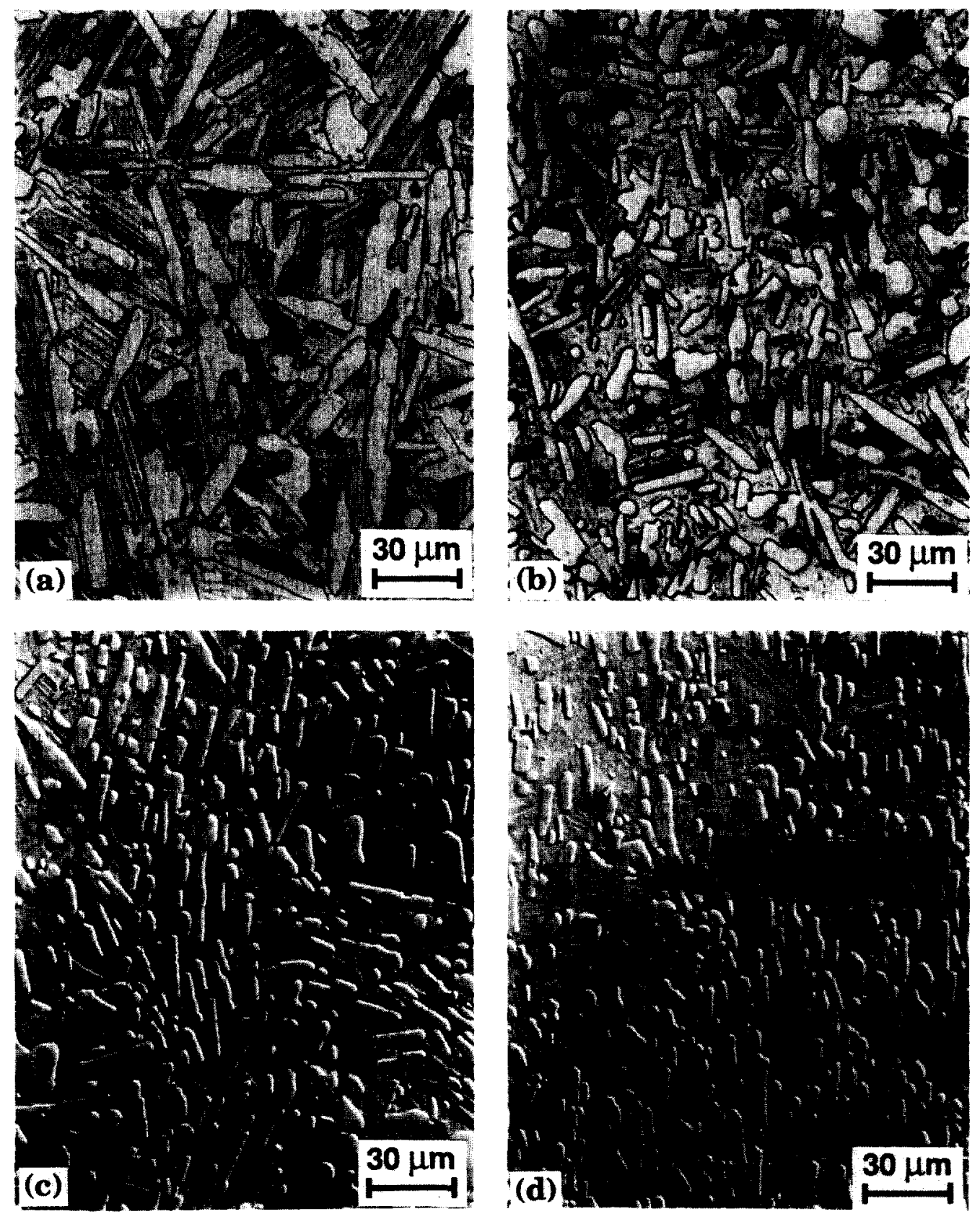

Fig. 9. Optical micrographs of $\mathrm{Ti}-48 \mathrm{Al} / 13 \% \mathrm{AlTi}_{2} \mathrm{C}$ deformed at $1470{ }^{\circ} \mathrm{C}$ showing the breakdown of the $13 \% \mathrm{AlTi}{ }_{2} \mathrm{C}$ platelets during compression testing at strain rate $=0.67 \mathrm{~s}^{-1}$, (a) $\varepsilon=0(\mathrm{~b}) \varepsilon=0.34$ (c) $\varepsilon=0.92$ and (d) $\varepsilon=1.63$. Stress axis is horizontal. 
sample. The deformed samples, Figs. 9(b), 9(c) and $9(\mathrm{~d})$, were compressed at $1470{ }^{\circ} \mathrm{C}$ and a strain rate of $0.67 \mathrm{~s}^{-1}$. It is clear from these micrographs that the number of reinforcement platelets increased and their size decreased significantly with increasing strain. Using the intercept method, the average size of the platelets was found to decrease from $8.76 \mu \mathrm{m}$ in the asreceived condition to $6.45 \mu \mathrm{m}$ and $4.83 \mu \mathrm{m}$ after deformation to strains of 0.34 and 0.92 , respectively. A sample (not shown in the micrograph) that had been deformed to 0.61 , produced platelets of an average size of $5.73 \mu \mathrm{m}$. However, this trend continued with strain except that at very high strains (i.e. 1.63), reagglomeration of the platelets was observed. The average aspect ratio of these platelets had also decreased with strain, from an average value of 8 in the as-received condition, to an average value of 3 after a strain of 1.63. In addition, it should be noted that most of the $\mathrm{AlTi}_{2} \mathrm{C}$ platelets are found to align themselves in the direction perpendicular to the stress compression which is horizontal on these micrographs. Thus, platelet breakdown and alignment occur simultaneously.

The phenomenon of platelet breakdown is shown quantitatively in Fig. 10 which illustrates the variation of the density of $\mathrm{AlTi}_{2} \mathrm{C}$ platelets of a particular size as a function of platelet size. This graph is derived from a set of histograms generated at every strain level. The measurements for the histograms were performed on the same area of the micrographs corresponding to $0.036 \mathrm{~mm}^{2}$ on the samples. It is also clear from this graph that the number of the platelets with a small size increased dramatically with strain. For example, in the actual $0.036 \mathrm{~mm}^{2}$ area, the number of platelets smaller than $50 \mu \mathrm{m}^{2}$ had increased from 27 at $\varepsilon=0$ to 215 at $\varepsilon=1.63$ whereas the total number of the platelets in the same area had only tripled after that deformation. At a high strain level of 1.63 , a bimodal platelet size distribution was observed in which very large platelets were

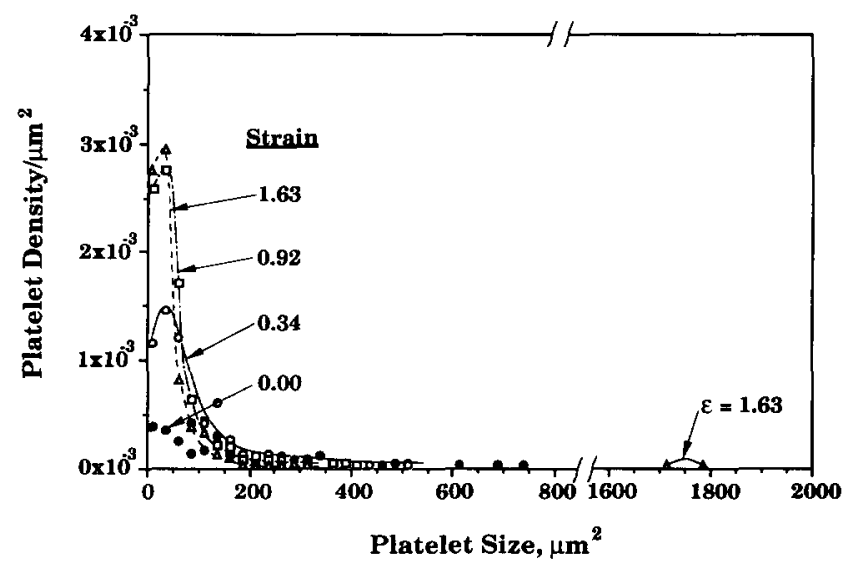

Fig. 10. Density of $\mathrm{AlTi}_{2} \mathrm{C}$ platelets as a function of their size for $\mathrm{Ti}-48 \mathrm{Al} / 13 \% \mathrm{AlTi}_{2} \mathrm{C}$ composite deformed to different strain levels at $1470{ }^{\circ} \mathrm{C}$, strain rate $=0.67 \mathrm{~s}^{-1}$. formed. These large platelets were the result of agglomeration of the platelets as seen in Fig. 9(d). However, this phenomenon of agglomeration is seen to occur at strains higher than 0.9 . While more data is required to ascertain this trend, it is possible that deformation-induced diffusion processes might play a role in further agglomeration of the platelets.

\section{Summary}

The deformation behavior of a two-phase lamellar $\left(\gamma+\alpha_{2}\right)-\mathrm{TiAl}$ and $\mathrm{TiAl}$ reinforced with $\mathrm{AlTi}_{2} \mathrm{C}$ has been investigated using indentation technique and compression testing. The composite materials showed an improvement in hardness only at $900{ }^{\circ} \mathrm{C}$ and this strength improvement became less significant with increasing temperature to $1300{ }^{\circ} \mathrm{C}$. Microcracking had been observed only around indentations performed at room temperature on the composites. These microcracks propagated in the matrix material, at the interface as well as in the $\mathrm{AlTi}_{2} \mathrm{C}$ platelets. In the base material, no major microcracks are produced as a result of indentation. These features indicate that these materials possess a reasonable degree of toughness. During compression testing in the semi-solid state, it is seen that the platelets start to break down at a critical strain level between 0.2 and 0.4 , a phenomenon previously reported in two-phase metallic alloys containing dendritic microstructure. The size of platelets was found to decrease, especially in the longitudinal direction, with increasing strain as the platelets were found to align in a direction normal to the compression axis. The aspect ratio of the platelets decreased from an average value of 8 in the undeformed condition to an average value of 3 at a strain of 1.63. Moreover, the number of platelets increased dramatically with strain as a result of their breakdown. However, at strains higher than 0.9 , the platelets reagglomerate leading to a bimodal size distribution.

\section{Acknowledgments}

The authors gratefully acknowledge Marko Materials for financial support and for supplying the test materials. Thanks are extended to Mr. Carl M. Lombard of Wright-Patterson Laboratories for reading the manuscript and helpful discussions.

\section{References}

1 D. M. Dimiduk, D. B. Miracle and C. H. Ward, Development of intermetallic materials for aerospace systems, Mater. Sci. Technol., 8(1992) 367-375. 
2 M. Yamaguchi, High temperature intermetallics-with particular emphasis on TiAl, Mater. Sci. Technol., 8 (1992) 299-307.

3 M. Dahms, F. Schmelzer, J. Seeger and B. Wildhagen, Microstructure and mechanical properties of $\gamma$ base titanium aluminide produced from extruded elemental powders, Mater. Sci. Technol., 8(1992) 359-362.

4 C. K. Elliott, G. R. Odette, G. E. Lucas and J. W. Sheckherd, Toughening mechanisms in intermetallic $\gamma$-TiAl alloys containing ductile phases, in F. D. Lemkey, S. G. Fishman, A. G. Evans and J. R. Strife (eds.), High Temperature/High Performance Composites, Mater. Res. Soc. Symp. Proc., Pittsburgh, PA, Vol. 120, 1988, pp. 95-102.

5 J. P. A. Lofvander, S. A. Court, H. L. Fraser, D. G. Konitzer and R. Kirchheim, The thermal stability of a refined dispersion of erbia particles in rapidly solidified $\mathrm{Ti}-\mathrm{Er}$ and Ti-Al-Er alloys, in F. H. Froes and S. J. Savage, Processing of Structural Metals by Rapid Solidification, ASM International, Metals Park, OH, 1987, pp. 231-241.

6 S. M. L. Sastry, P. J. Meschter and J. E. O'Neal, Structure and properties of rapidly solidified dispersion-strengthened titanium alloys: Part 1. Characterization of dispersoid distribution, structure and chemistry, Metall. Trans. A, 15A (1984) 1451-1463.

7 K. S. Kumar and J. D. Whittenberger, Discontinuously reinforced intermetallic matrix composites via XD synthesis, Mater. Sci. Technol., 8(1992) 317-330.

8 M. E. Hyman, C. McCullough, J. J. Valencia, C. G. Levi and R. Mehrabian, Microstructure evolution in TiAl alloys with $\mathrm{B}$ additions: conventional solidification, Metall. Trans., $20 \mathrm{~A}$ (1989) 1847-1859.

9 H. E. Deve, A. G. Evans, G. R. Odette and R. Mehrabian, Ductile reinforcement toughening of $\gamma$-TiAl: effects of debonding and ductility, Acta Metall. Mater., 38 (8) (1990) 1491-1502.

10 R. Mehrabian, New pathways to processing composites, in F. D. Lemkey, S. G. Fishman, A. G. Evans and J. R. Strife (eds.), High Temperature/High Performance Composites, Mater. Res. Soc. Symp Proc., Pittsburgh, PA, Vol. 120, 1988, pp. 3-21.

11 J. Rosler, J. J. Valencia, C. G. Levi, A. G. Evans and R. Mehrabian, The high temperature behaviour of TiAl containing carbide reinforcement, in D. L. Anton, P. L. Martin, D. B. Miracle and R. McMeeking (eds.), Intermetallic Matrix Composites, Mater. Res. Soc. Symp. Proc., Pittsburgh, PA, Vol. 194, 1990, pp. 241-248.

12 Y.-W. Kim and D. Dimiduk, Progression in the understanding of gamma titanium aluminides, J. Organometall. Chem., $43(8)(1991) 40-47$.

13 Y.-W. Kim, Intermetallic alloys based on gamma titanium aluminide. J. Organometall. Chem., 41 (7) (1989) 24-30.

14 T. Kawabata, T. Kanai and O. Izumi, A mechanism of the positive temperature dependence of yield stress in TiAl, in L. A. Johnson, D. P. Pope and J. O. Stiegler (eds.), HighTemperature Ordered Intermetallic Alloys IV, Mater. Res. Soc. Symp. Proc., Pittsburgh, PA, Vol. 213, 1991, pp. 279-284.
15 E. L. Hall and S.-C. Huang, Stoichiometry effects on the deformation of binary TiAl alloys, J. Mater. Res., 4 (3) (1989) 595-602.

16 S.-C. Huang and E. L. Hall, Microstructure and deformation of rapidly solidified TiAl alloys, in C. T. Liu, A. I. Taub, N. S. Stoloff and C. C. Koch (eds.), High-Temperature Ordered Intermetallic Alloys III, Mater. Res. Soc. Symp. Proc., Pittsburgh, PA, Vol. 133, 1989, pp. 373-383.

17 T. Kawabata, M. Tadano and O. Izumi, Effects of purity and second phase on ductility of TiAl, Scripta Metall., 22 (1988) $1725-1730$.

18 Y. D. Hahn, Z. X. Li and S. H. Whang, Dislocation structure in single crystal L1o type $\mathrm{Ti}-\mathrm{Al}-\mathrm{V}$ compound, in $\mathrm{L}$. A. Johnson, D. P. Pope and J. O. Stiegler (eds.), HighTemperature Ordered Intermetallic Alloys IV, Mater. Res. Soc. Symp. Proc., Vol. 213, 1991, pp. 291-296.

19 S.-C. Huang and E. L. Hall, Plastic deformation and fracture of binary TiAl-base alloys, Metall. Trans., 22A (1991) 427-439.

20 L. Christodoulou, P. Parrish and C. R. Crowe, XD titanium aluminide composites, in F. D. Lemkey, S. G. Fishman, A. G. Evans and J. R. Strife (eds.), High Temperature/High Performance Composites, Mater. Res. Soc. Symp. Proc., Pittsburgh, PA, Vol. 120, 1988, pp. 29-34.

$21 \mathrm{~K}$. S. Chan, Influence of microstructure on intrinsic and extrinsic toughening in an Alpha-two titanium aluminide alloy, Metall. Trans., 23A (1992) 183-199.

22 M. C. Flemings, Rheocasting, Year Book of Science and Technology, McGraw-Hill, New York, 1978, pp. 42-58.

23 M. C. Flemings, Behavior of metal alloys in the semisolid state, Metall. Trans., 22A (1991) 957-981.

24 V. Laxmanan and M. C. Flemings, Deformation of semisolid Sn-15 Pct $\mathrm{Pb}$ alloy, Metall. Trans., 11A (1980) 1927-1937.

$25 \mathrm{M}$. Kiuchi and S. Sugiyama, Manufacturing of metal-ceramics composites by mashy-state processings, in H. Y. Sohn and E. S. Geskin (eds.), Metallurgical Processes for the Year 2000 and Beyond, The Minerals, Metals and Materials Society, Warrendale, PA, 1988, pp. 83-100.

26 M. Suery and M. C. Flemings, Effects of strain rate on deformation behavior of semi-solid dendritic alloys, Metall. Trans., 13A (1982) 1809-1819.

27 R. Ayer, R. Ray and J. C. Scanlon, Analytical microscopy of an in-situ $\gamma$-TiAl composite containing a carbide phase, Scripta Metall., 26(9)(1992) 1337-1342.

28 J. J. Valencia, C. McCullough, J. Rosler, C. G. Levi and R. Mehrabian, in Solidification of Metal Matrix Composites, TMS, Warrendale, PA, 1990.

29 X. Cai and P. N. Zhou, Influence of elastic recovery on microindentation hardness, Scripta Metall., 27 (1992) 347-352.

$30 \mathrm{R}, \mathrm{K}$. Wade and J. J. Petrovic, Fracture modes in $\mathrm{MoSi}_{2}$, J. Am. Ceram. Soc., 75(6)(1992) 1682-1684.

31 S.-C. Huang and E. L. Hall, Microstructure and deformation of rapidly solidified TiAl alloys, in C. T. Liu, A. I. Taub, N. S. Stoloff and C. C. Koch (eds.), High-Temperature Ordered Intermetallic Alloys III, Mater. Res. Soc. Symp. Proc., Pittsburgh, PA, Vol. 133, 1989, pp. 373-383. 